\title{
Feasibility of a virtual Facebook community platform for engagement on health research
}

www.cambridge.org/cts

\section{Implementation, Policy and Community Engagement Research Article}

Cite this article: Patten CA, Balls-Berry JE, Cohen EL, Brockman TA, Valdez Soto M, West IW, Cha J, Zavala Rocha MG, and Eder M. Feasibility of a virtual Facebook community platform for engagement on health research. Journal of Clinical and Translational Science 5: e85, 1-7. doi: 10.1017/cts.2021.12

Received: 24 November 2020

Revised: 10 February 2021

Accepted: 11 February 2021

\section{Keywords:}

Social media; virtual; digital; community engagement; COVID-19

\section{Address for correspondence:}

C. A. Patten, PhD, Department of Psychiatry and Psychology and Center for Clinical and Translational Science Mayo Clinic, 200 First St SW, Rochester, MN 55905, USA.

Telephone: (507) 538-7370.

Email: patten.christi@mayo.edu

\section{${ }^{*}$ Dr. Balls-Berry is now with Washington} University School of Medicine in St. Louis, MO, USA.

(c) The Author(s), 2021. Published by Cambridge University Press on behalf of The Association for Clinical and Translational Science. This is an Open Access article, distributed under the terms of the Creative Commons AttributionNonCommercial-NoDerivatives licence (http:// creativecommons.org/licenses/by-nc-nd/4.0/), which permits non-commercial re-use, distribution, and reproduction in any medium, provided the original work is unaltered and is properly cited. The written permission of Cambridge University Press must be obtained for commercial reuse or in order to create a derivative work

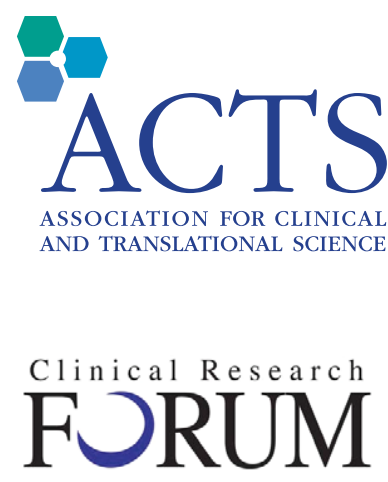

Analysis. Advocacy. Action.

\author{
Christi A. Patten ${ }^{1}$, Joyce (Joy) E. Balls-Berry ${ }^{2, \star}$, Elisia L. Cohen ${ }^{3}$, \\ Tabetha A. Brockman ${ }^{1}$, Miguel Valdez Soto ${ }^{2}$, Ian W. West ${ }^{1}$, Jinhee Cha ${ }^{4}$, \\ Maria G. Zavala Rocha ${ }^{1}$ and Milton (Mickey) $\operatorname{Eder}^{5}$ (i)
}

${ }^{1}$ Department of Psychiatry and Psychology and Center for Clinical and Translational Science, Mayo Clinic, Rochester, MN, USA; ${ }^{2}$ Center for Clinical and Translational Science, Mayo Clinic, Rochester, MN, USA; ${ }^{3}$ Hubbard School of Journalism \& Mass Communication, University of Minnesota, Minneapolis, MN, USA; ${ }^{4}$ School of Public Health, University of Minnesota, Minneapolis, MN, USA and ${ }^{5}$ Department of Family Medicine and Community Health, Medical School and the Clinical and Translational Science Institute, University of Minnesota, Minneapolis, MN, USA

\begin{abstract}
Introduction: Community engagement is important for advancing Clinical and Translational Science (CTS), but face-to-face engagement has limited reach and scale. We examined the feasibility of a novel virtual Facebook community platform for public engagement on health research statewide in Minnesota. Methods: The Facebook platform, MN Research Link, was evaluated from June 19, 2019 to June 30, 2020. Facebook advertisements and boosts were used to recruit followers. Content, based on prior formative work, included health research information and interactive postings (e.g., live interviews with researchers). Standard metrics obtained from Facebook analytics included participation (followers), content reach (views), and engagement (likes, shares, comments, clicks). Results: During the 12-month period, we acquired 1406 followers (31\% rural residents), with a retention of followers of $99.7 \%$. Mean number of views per month was $9379.83(\mathrm{Mdn}=2791$, range $724-41,510)$. Engagement metrics indicated a mean of 535.2 likes, shares, comments, and/or clicks per month ( $\mathrm{Mdn}=296.5$, range 55-1535). The page continued to acquire new followers, but a slight decrease in engagement was observed in the final months after state COVID-19 mitigation strategies were implemented. Conclusion: As the complexity of CTS continues to grow, along with social distancing measures resulting from the COVID-19 pandemic, the availability of virtual digital platforms to reach and engage community stakeholders in conversations about health and research has increasing importance. Preliminary findings from this program evaluation indicate that a Facebook community platform is feasible to engage Minnesota residents in conversations around health and research topics. Future work will evaluate its potential for reach, scale, and sustainability.
\end{abstract}

\section{Introduction}

Community engagement is increasingly viewed as essential for advancing Clinical and Translational Science (CTS) and improving the public health [1-4]. Engagement strategies to promote bidirectional conversations with stakeholders on health research include Community Engagement Studios [5], Science Cafés [6], Garden Cafés [7], the HealthStreet model [8], and Community Advisory Boards [9,10]. While effective, these face-to-face community outreach forums have limited reach and scale. With the COVID-19 pandemic and associated limits to group meetings and recommended social distancing measures to limit exposure, digital platforms hold promise as alternative channels to reach the broader public and enhance access to and engagement with CTS research $[11,12]$. In this program evaluation, our community-engaged research team at the Mayo Clinic (CTSA) and University of Minnesota (CTSI) NIH-funded centers for CTS evaluated the feasibility of a virtual, statewide, Facebook community platform to enhance public engagement with health research in Minnesota. Studies reported on the successful use of social media for participant recruitment to clinical trials and other research $[13,14]$. However, to our knowledge, this is the first report of a social mediaformed virtual community within the NIH-funded CTS Consortium.

Social media tools are widely adopted in the population. Nationally, YouTube and Facebook are the dominant social networking platforms used by $73 \%$ and $69 \%$ of online US adults, respectively [15]. Facebook use is similar across sociodemographic groups and geographic location (rural/urban), except for less use among men, those with less than a high school education and adults aged 65 and older [15]. A 2018 study conducted statewide in Minnesota explored the use of social media options for public engagement on transportation issues [16]. Among 800 adult respondents, $72 \%$ reported using social media. Among social media users, 
Facebook had the highest use (92\%) and daily use (88\%) compared to YouTube or other platforms.

Formative work at Mayo Clinic indicated diverse community members in Minnesota preferred to receive information about health and research through social media platforms [17,18]. Further, community member participants at Garden Cafés shared a desire for continued dialogues about research through social media [7]. In pilot evaluations of two digital platforms (Twitter and a Web blog), content analysis of comments posted by community members indicated a key theme of increased awareness about health research and research findings (i.e., dissemination) [19].

At the 2018 Minnesota state fair, our research team assessed adult Minnesota residents' willingness and readiness to engage in a virtual Facebook community for conversations on health and research topics [20]. Among survey respondents with a personal Facebook profile ( $n=418 ; 66 \%$ women), about half $(46 \%)$ agreed/strongly agreed they would be willing to join a Facebook page focusing on health and research topics. Content analysis of the open-ended survey questions indicated the types of information people wanted, the health topics people wanted to learn more about, and what would keep people engaged and interested. Based on this collective formative work, the research team created the Facebook page MN Research Link, a public, statewide, social media virtual platform to provide credible evidence-based health information and engage Minnesota residents in conversations on health and research topics. In this program evaluation, we assessed the feasibility of this Facebook community platform as indicated by participation, reach, and engagement. Because social media can be used to reach individuals in remote rural areas [12,15], we also assessed the proportion of our Facebook followers from rural counties.

\section{Materials and Methods}

The Mayo Clinic (CTSA) and the University of Minnesota (CTSI) NIH-funded CTS Community Engagement Programs partnered to design the Facebook platform and evaluation. The project was deemed exempt by the Mayo Clinic and University of Minnesota Institutional Review Boards.

\section{Study Design}

This program evaluation assessed uptake and engagement with the Facebook community platform MN Research Link from June 19, 2019 to June $30,2020$.

\section{Facebook Page Design and Facilitation}

The research team worked with social media and digital health experts at Mayo Clinic to design a public Facebook page titled MN Research Link. The goal of the MN Research Link was to serve as a credible source of health research information and research dissemination in Minnesota, and ultimately to enhance the public's trust and engagement in health research.

Over the 12-month evaluation period, the MN Research Link page was facilitated by four social media managers (JC, IW, MVS, MZR). At any one time, the MN Research Link was facilitated by one-two individuals. Facilitators posted content daily. They scheduled live events and conducted interviews with researchers. Facilitators checked the page daily to review comments from followers. During the evaluation period, the four facilitators, along with four research team members (CAP, JBB, ELC, TAB) followed the page, but aside from posting content and sharing live events, team members were encouraged to have minimal engagement with the page.

\section{MN Research Link Facebook Content}

The project team collectively developed the content for the Facebook page. The research team has complementary expertise in community engagement, health communication, health education, psychology, behavioral science, epidemiology, and public health. We took into account the recommendations for developing health communication to engage stakeholders through social media platforms [21] and social media post design for Facebook [22].

Table 1 shows the major content domains for the postings and months the content was posted. Content included both noninteractive postings (e.g., research articles related to health research) and interactive postings/events (e.g., live interviews with researchers). Content for health topics was prioritized based on preferences suggested in our prior survey [20], including mental health, health and wellness (e.g., nutrition, physical activity), chronic diseases (e.g., cardiovascular disease), and immunology/infectious diseases. The onset of COVID-19 changed some of the posting plans for $M N$ Research Link. In response to the global pandemic and associated stay-at-home restrictions and masking mandate in Minnesota, beginning month 6 of the evaluation, content was added on COVID-19 and masking as a preventive strategy. Another topic receiving attention in the news media during the program evaluation period was the health effects of vaping/electronic cigarette use; therefore, content was created to address this topic. Our prior survey [20] indicated that individuals wanted credible, accurate, and reliable health information and provision of research findings, as well as information about participating in research. For health topics, findings from research studies including research articles were included with a prioritization of research articles and studies with a connection to the Minnesota community. We also hosted live events where investigators shared information about their health research studies. These consisted of structured interviews with a question and answer session to foster bidirectional communication.

Content was also posted on general research topics such as, "What happens when a person enrolls in a clinical trial?" (see Table 1). Additional content was designed to engage and keep people interested in the Facebook page, as recommended by survey respondents [20]. These included holiday recipes, health reminders, and pets as well as live events and polls. An example of a poll was "Would you like to learn more about vaping?" with a yes or no response option.

As a way to plan and organize content [23], weekly social media content calendars were devised, focusing on several different topics; see Fig. 1, for example. A link post is a post that contains a direct link to other content, for example, video or research article.

Facebook postings created by the research team included: (1) brief videos with an average duration of about 10-12 min, (2) text written in the English language and limited to about 120 characters [23], and (3) combined images with text, which has been shown to increase Facebook user engagement by $84 \%$ over text-only posts $[24,25]$. Where possible, the posting approach structured a claim with evidence and cue to action that was directed to laypeople. Posts also tagged the names of public health partner organizations where used, following best practice of social media post design for Facebook recommended by the CDC [22]. Facebook was used to post content that was actionable, asked users to do something 
Table 1. Content domains and illustrative topics of MN Research Link Facebook postings

\begin{tabular}{|c|c|}
\hline Content categories & $\begin{array}{l}\text { Months } \\
\text { posted }\end{array}$ \\
\hline \multicolumn{2}{|l|}{ 1. Health research information (research studies/findings) } \\
\hline Mental health & All \\
\hline $\begin{array}{l}\text { Health and wellness (e.g., nutrition, physical activity/ } \\
\text { exercise, healthy aging, disease prevention) }\end{array}$ & All \\
\hline Chronic diseases (e.g., cardiovascular health, cancer) & $\begin{array}{c}1,2,4,6,8 \\
9,11\end{array}$ \\
\hline $\begin{array}{l}\text { Immunology/infectious diseases (e.g., Lyme disease, } \\
\text { vaccines) }\end{array}$ & $\begin{array}{l}6,7,9,10 \\
11,12\end{array}$ \\
\hline COVID-19 & $7-12$ \\
\hline Electronic nicotine delivery devices (ENDs)/vaping & $6-9$ \\
\hline $\begin{array}{l}\text { Health care (e.g., access barriers, integrated health } \\
\text { care, palliative care) }\end{array}$ & All \\
\hline $\begin{array}{l}\text { Miscellaneous (e.g., rural health, health disparities, } \\
\text { community outreach) }\end{array}$ & $\begin{array}{c}1,4,5,6,10 \\
11,12\end{array}$ \\
\hline \multicolumn{2}{|l|}{ 2. General research topics } \\
\hline $\begin{array}{l}\text { Examples: clinical research and trust, scientific mistrust, } \\
\text { clinical trials, health technology, stem cell research, } \\
\text { immunology }\end{array}$ & All \\
\hline \multicolumn{2}{|l|}{ 3. Interactive posts } \\
\hline Polls & 8 \\
\hline $\begin{array}{l}\text { Live Facebook events, that is, interview and chat dis- } \\
\text { cussion with the researcher }\end{array}$ & $1-9,11,12$ \\
\hline Questions directed to followers & 11,12 \\
\hline \multicolumn{2}{|l|}{ 4. Miscellaneous topics to stimulate interest and engagement } \\
\hline $\begin{array}{l}\text { Examples: holiday recipes, pets, fun topics (e.g., foods } \\
\text { available at the MN state fair), health reminders, com- } \\
\text { munity events, and resources (e.g., where to get flu } \\
\text { shots) }\end{array}$ & All \\
\hline
\end{tabular}

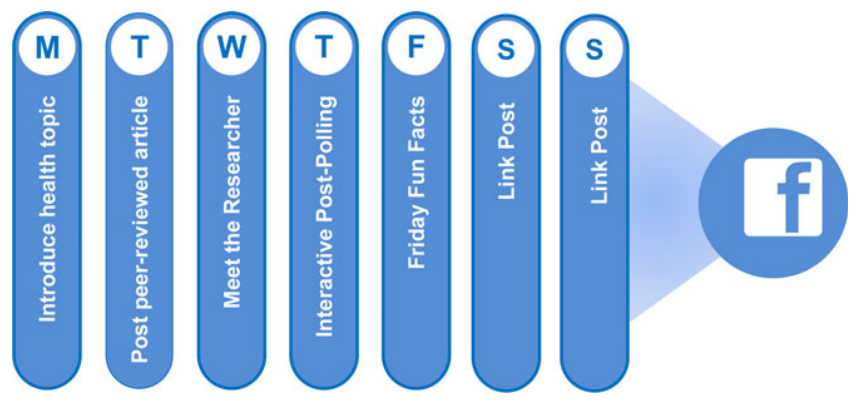

Fig. 1. The MN Research Link Facebook topic scheduling.

within the posts, highlighted posts that encouraged CTS priorities by pinning or adding a milestone on the timeline, cross-promoted other social media channel content, and added information rather than removed comments that were not reflective of science [22]. During the 12 -month period, a total of 328 posts were created, including $30 \mathrm{MN}$ Research Link live events and 4 polls.

\section{MN Research Link Facebook Recruitment}

To enhance the reach of the MN Research Link statewide in Minnesota, 221 targeted Facebook advertisements or boosts were created, of which 20 targeted rural populations. The advertisements targeted residents of Minnesota statewide and aged 18 years or older. The Facebook page was also promoted using flyers and during presentations at community outreach events. University and community partners were asked to share the MN Research Link page on their organization's Facebook page and with individuals in the community.

\section{Feasibility Measures}

\section{Participants}

We used Facebook analytics [26] to assess the number of new and total followers each month, an indicator of those who have joined the MN Research Link community [23]. The minimum number of social media followers recommended for adequate engagement is 200 [27]. Our goal was to have 500 or more followers by the end of the 12-month period. Retention was calculated as the proportion of total followers who had not unfollowed the page by the end of the evaluation period [23].

To estimate the representativeness of our followers from rural areas, a random sample of $25 \%$ of our 1400 followers was generated and coded for rural/non-rural location in Minnesota, based on the US Census Bureau [28] classification. Followers were listed using a unique project ID number. Using a random number generator, 376 numbers were then created. The range 1-1400 was used for the parameters of the number generator and the 376 random numbers created corresponded to the project ID list of followers. Using the list of rural counties from the Minnesota Department of Health US census, each of the 376 IDs was classified as rural or non-rural based on the current county and/or city listed on their Facebook profile. Some individuals $(n=39)$ did not list location information on their Facebook profiles. Thus, 337 samples were used in calculations.

To calculate participation reach to the estimated Minnesota adult population using Facebook, we used the US Census Minnesota population estimates [29], and US Internet [30] and social media use [15] statistics. As of July 1, 2019, the Minnesota population estimate was 5,639,632 people, of which $76.9 \%(4,336,877)$ people were aged 18 or older. We further assumed that $90 \%(3,903,189)$ were online/Internet users, of which $73 \%(2,849,328)$ used Facebook. Participant reach was calculated as the total number of followers to our Facebook page during the 12-month period divided by the denominator of 2,849,328 potential Facebook users in Minnesota. We further calculated the total cost of advertising through Facebook ads and boosts, and the advertising cost per follower.

\section{Content Reach (Views)}

Another measure of the reach of our Facebook page was the number of views of our postings among Facebook users, whether or not they were followers to the MN Research Link [23]. For example, if one of our followers liked or shared a posting, it would be included in the news feed of all of their friends' Facebook accounts, who each had an opportunity to view the posting. Number of views per month was calculated using Facebook analytics [26].

\section{Facebook Engagement Among Followers}

Standard engagement metrics [23] obtained from Facebook analytics [26] provided monthly, cross-sectional, de-identified, group-level data for the population of followers. The data were not provided at the level of individual followers nor were patterns of individual participant engagement represented over time. For 
each month, the number of follower likes, shares, comments, and clicks (defined as taking action on a posting by clicking on it to view a photo or expand to read a post, or on a post link to play a video or read a research article) was calculated. Engagement metrics were summarized independently, thus participants may have contributed to more than one metric. For example, if a participant both liked and shared a posting, these data were included in both the total likes and total shares. In addition, it is possible that participants may have clicked on several postings and/or clicked multiple times on the same video or other posting for which all were included in the monthly total for clicks. The engagement metrics were summed to create a monthly total engagement measure.

\section{Statistical Methods}

Descriptive statistics were implemented to summarize the reach and engagement with the Facebook page over a 12-month period.

\section{Results}

\section{Participants}

Figure 2 shows the number of new and total followers each quarter. At the start of the evaluation, there were no followers. During the first quarter, the page gained 99 followers. During the 12-month period, we acquired a total of 1406 followers, or about 117 per month; 4 individuals unfollowed the Facebook page. From 6 to 12 months, we increased the total number of followers by $81 \%$ (from 272 to 1402). The participation reach was estimated at $4.9 \%(1406 / 2,849,328)$. The total cost for Facebook ads/boosts was $\$ 1359$ or less than $\$ 1$ ( $\$ 0.97)$ per follower. Representativeness of rural residents among followers was estimated at 30.8\% (104 of 337 profiles randomly sampled).

\section{Content Reach (Views)}

Figure 3 shows the number of posting views per month among followers and non-followers. Mean number of views per month was $9379.83(\mathrm{Mdn}=2791)$, range $724-41,510$.

\section{Facebook Engagement Among Followers}

Figure $4 \mathrm{~A}$ shows the number of postings made each month and Fig. $4 \mathrm{~B}$ displays the engagement among our followers each month. The mean number of posts per month was 27.33, standard deviation $(S D)=10.96, \mathrm{Mdn}=26$, range 14-49. Engagement metrics indicated a mean of $535.17(S D=596.12, \mathrm{Mdn}=296.5)$ likes, shares, comments, and/or clicks each month, range 55-1,535. Increases in engagement occurred in months 3 and 4 toward the beginning of the evaluation period as well as in months 7 and 9, but decreases were observed in the last quarter.

\section{Discussion}

A novel finding of our program evaluation is that Facebook is a feasible platform to engage a virtual Minnesota community on health and research topics. The number of followers to the Facebook page increased significantly (by $81 \%$ ) over the 12 months of evaluation, and the total number of followers (1406) exceeded our goal of 500. Moreover, retention in this digital community was extremely high; 1402 of 1406 (99.7\%). Representativeness of rural residents among our followers was estimated at $31 \%$, which

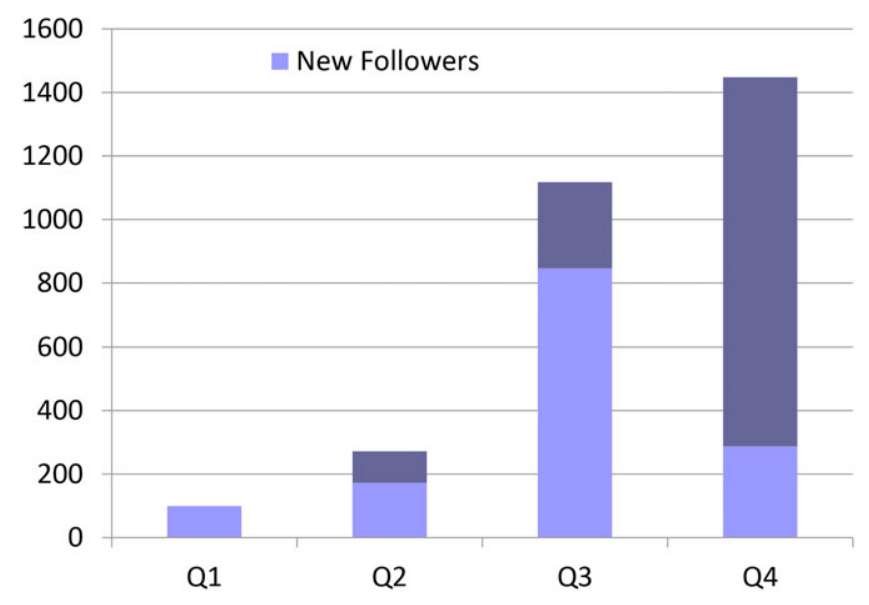

Fig. 2. Number of followers to the MN Research Link Facebook page by quarter, June 2019-June 2020.

compares favorably to data indicating that $27 \%$ of the Minnesota adult population lives in rural areas [31]. Our followers engaged with the Facebook page, with an average of 535 likes, shares, comments, and/or clicks to postings per month. Our preliminary data demonstrate Facebook as a feasible channel for engaging a virtual community and provide a model for the CTSA Consortium for community outreach. Our findings are particularly timely and relevant given the current societal challenges with in-person connectivity and the increasing reliance on social media and other digital platforms due to COVID-19 [32].

The number of postings made each month generally mirrored the pattern of engagement and views (see Figs. 4A and 4B). The reasons for the large spike in engagement and views in months 3 and 4 relative to the number of postings is uncertain other than the efforts by the research team to recruit new followers. Table 1 does not suggest any unique content during this time. Decreases in postings, engagement, and views in months 5 and 6 could be explained by facilitator (staff) turnover at this time. Subsequent increases in engagement and views in months 7 and 9 could be due to new topics posted during this time on COVID-19 and ENDs/vaping (Table 1). Though engagement and views varied across months, our finding that a digital platform is feasible is encouraging given the program evaluation period coincided with the global COVID-19 pandemic. The effects of the COVID-19 pandemic on user engagement are uncertain. It is possible that the pandemic in Minnesota enhanced individual connectivity to social media or magnified individual media use overall. However, it is also possible that the "stay at home order" and fatigue over media stories of COVID-19 during this period increased individuals' disengagement with news media as well as decreased engagement with our page in the final months of the evaluation. The last quarter of the evaluation also coincided with the Minnesota "stay at home order" enacted in response to the COVID-19 pandemic. Our followers may have needed to prioritize their attention on safety, family health, and ensuring adequate grocery and essential supplies; while some possibly dealt with changes in their work environments like working from home or reduced hours, unemployment, furloughs, and at-home schooling. Given the closure of clinical facilities and a choice to delay seeking care when available, it is also possible that people did not want to engage with content on health topics. Nevertheless, during this period the page continued to engage new followers. 


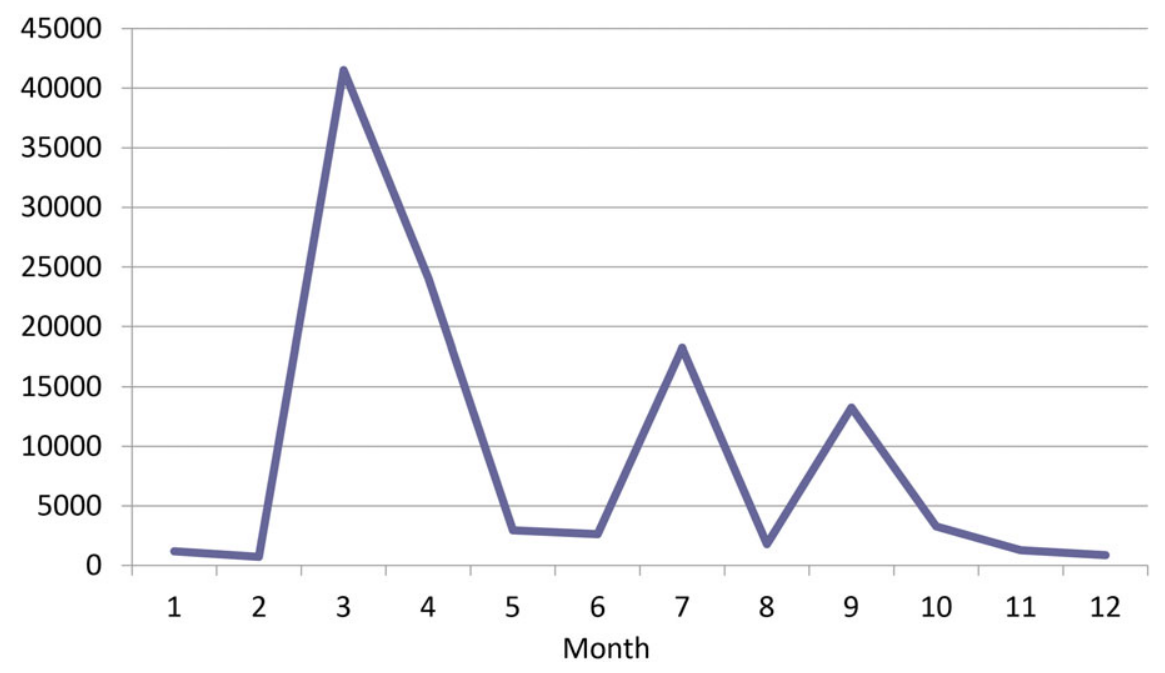

Fig. 3. Number of MN Research Link posting views by Facebook users (content reach) per month.

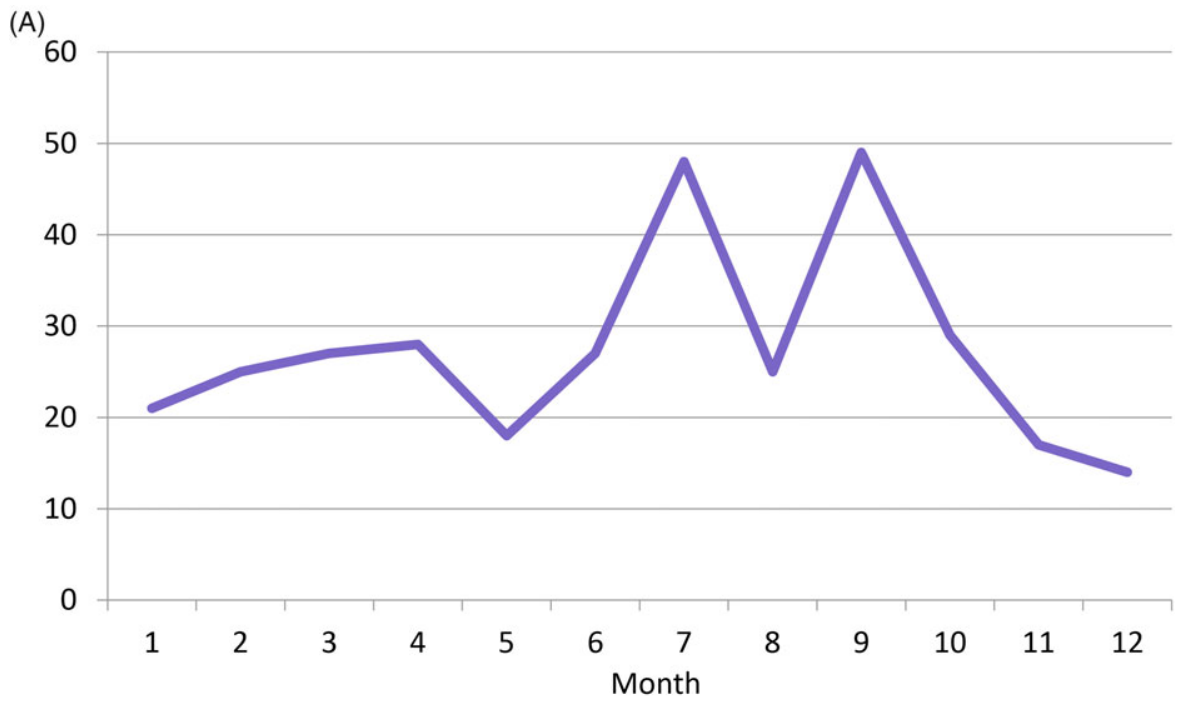

(B)

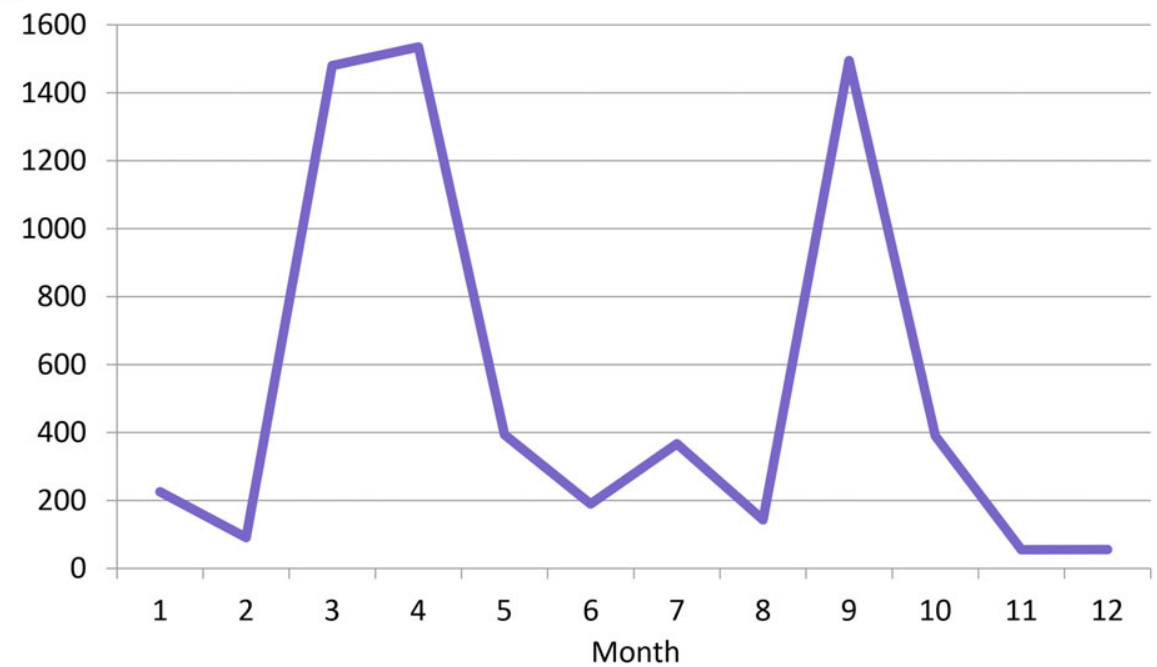

Fig. 4. (A) Postings to the MN Research Link Facebook page by month, June 2019-June 2020. (B) Engagement among followers to the MN Research Link Facebook page by month, June 2019-June 2020. 


\section{Limitations}

Our Facebook page was designed for and with input from Minnesota residents, so the results may not be replicable with individuals from other geographic locations. Our estimate of rurality was limited to the participants' Facebook profile information and may have been under or overestimated. We did not assess the sociodemographic characteristics of followers. Our program evaluation was limited to a 12-month period; participation, engagement, and reach long-term need additional study. Engagement metrics were limited to cross-sectional, aggregate data among followers and were not based on individual participantlevel data. While we observed high retention of followers, it is not certain if the majority of the group continued to engage with the page throughout the evaluation period.

\section{Strengths}

Based on substantial formative work, we designed an innovative digital platform to engage adults in conversations around health and research topics. The number of followers and retention was excellent, enabling us to meaningfully evaluate engagement and content reach over a 12-month period. The platform was successful in reaching both urban and rural residents of Minnesota.

\section{Future Directions}

Prior studies of online communities revealed stages of joining, maintaining presence, and disengaging [33]. Our program evaluation assessed the first stage of joining. To enhance participation, we used Facebook ads and boosts, flyers, and community forums/ outreach. The reach of our participants (followers) compared to the MN adult online population using Facebook was estimated to be $5 \%$. Thus, strategies need to be implemented to expand the reach of followers, or those who will join the page. It is possible that with continued presence or exposure to Facebook postings among non-followers may eventually result in additional people joining MN Research Link. Because so many non-followers viewed our postings, future postings could promote our page with a call to action, for example, "Folllow Us!" with a QR code or other link to the Facebook page. Future communication and outreach efforts could use mass media and forming partnerships with organizations with larger Facebook followings (e.g., National Alliance on Mental Illness and rural Extension Offices) to promote and share our Facebook content to enhance its reach. An alternative approach is to plan more direct cross-channel promotion on other social media platforms like Twitter and Instagram as well as specific outreach to demographic groups more likely to use Facebook as well as other social networking sites. For example, young adults aged 18-24 are most likely to use Instagram compared to other age groups [34]. Of interest are potential changes in social with the COVID-19 pandemic. In a US sample of 1374 adults, $35 \%$ reported an increase in the use of social media platforms for communication compared to before the COVID-19 pandemic; 56\% reported the same and only $8 \%$ reported a decrease [32]. The oldest quartile of the sample was more likely to have reduced digital communications of any form and women were more likely than men to have increased communications. However, that study did not explore trends in the use of different types of social media platforms.

Future research will explore whether social media offers a scalable and sustainable engagement practice to provide credible, evidence-based health information and enhance bidirectional engagement about health and research. Future evaluations will assess implementation outcomes such as reach, adoption, and maintenance as well as cost-effectiveness. The ability to adjust criterion for group membership and focused sharing through privacy settings further expands the potential value of refining virtual communities around specific health and research topics. Moderating closed private groups would also allow us to conduct assessments of participant characteristics, health outcomes, and other factors such as community resilience and trust in research. This approach would also allow for the assessment of individual participant patterns and trajectories of engagement and retention.

Our long-term objective is to sustain a digital community of diverse voices and perspectives from across Minnesota. We have planned additional innovative and interactive methods to enhance engagement, such as holding Virtual Cafes and using Poll Everywhere. We also plan to form smaller, closed, private virtual groups to refine the Facebook content to focus on specific health topics of interest as well as cultural and linguistic identities among our followers. Smaller virtual communities can enhance engagement by fostering social support and connection [33]. A sustainable community could engage former or current group participants to volunteer as peer facilitators and to design and contribute content. Forming partnerships with health and community organizations that could promote and contribute to the page would enhance sustainability. To reduce facilitator time needed to maintain the page, existing content could be organized as a content library [23] and prescheduled for automated posting. Future work could also use artificial intelligence/machine learning tools to evaluate followers' comments to assess emerging health and research needs and interests in real time, and to tailor and automate content accordingly.

\section{Conclusions}

As the complexity of CTS continues to grow, along with social distancing measures resulting from the COVID-19 pandemic, the availability of virtual digital platforms to reach and engage community stakeholders in conversations about health and research has increasing importance. Preliminary findings from this program evaluation indicate that a Facebook community platform is feasible to engage Minnesota residents in conversations around health and research topics. Future work to evaluate its potential for reach, scale, and sustainability is warranted.

Acknowledgments. This project was supported by grant numbers UL1 TR002377 (Mayo Clinic CTSA) (CAP, JEB, TAB, MVS, IWW, MGZR), UL1 TR002494 (UMN CTSI) (ELC, JC, ME), and UL1 TR002494-S1 (UMN CTSI) (CAP, JEB, ELL, TAB, MVS, IWW, JC, MGZR, ME), from the National Center for Advancing Translational Sciences. Its contents are solely the responsibility of the authors and do not necessarily represent the official views of the National Institutes of Health.

We wish to thank Ida Darmawan BS Pharm, MBA, MA (University of Minnesota), and Martha Bock, Christine Hughes, and Lee Aase from Mayo Clinic for their contributions to this project. We thank Kimberly Kinnoin for manuscript assistance.

Disclosures. The authors have no conflicts of interest to disclose.

\section{References}

1. Centers for Disease Control and Prevention (CDC) Principles of Community Engagement. 2nd edition. Washington, DC: NIH; 2011. 
2. Institute of Medicine The CTSA Program At NIH: Opportunities for Advancing Clinical and Translational Research. Washington, DC: The National Academies Press; 2013.

3. Michener L, Cook J, Ahmed SM, Yonas MA, Coyne-Beasely T, AguilarGaxiola S Aligning the goals of community-engaged research: why and how academic health centers can successfully engage with communities to improve health. Academic Medicine 2012; 87: 285-291. doi: 10.1097/ ACM.0b013e3182441680.

4. Woolf SH, Zimmerman E, Haley A, Krist AH Authentic engagement of patients and communities can transform research, practice, and policy. Health Affairs (Millwood) 2016; 35: 590-594. doi: 10.1377/hlthaff.2015. 1512 .

5. Joosten YA, Israel TL, Williams NA, et al. Community engagement studios: a structured approach to obtaining meaningful input from stakeholders to inform research. Academic Medicine 2015; 90: 1646-1650. doi: 10.1097/ACM.0000000000000794.

6. Ahmed S, DeFino MC, Connors ER, Kissack A, Franco Z Science cafes: engaging scientists and community through health and science dialogue. Clinical and Translational Science 2014; 7: 196-200. doi: 10.1111/cts.12153.

7. Balls-Berry JE, Sinicrope PS, Valdez Soto MA, et al. Using garden cafes to engage community stakeholders in health research. PLoS One 2018; 13: e0200483. doi: 10.1371/journal.pone.0200483.

8. Cottler LB, McCloskey DJ, Aquilar-Gaxiola S, et al. Community needs, concerns, and perceptions about health research: findings from the clinical and translational science award sentinel network. American Journal of Public Health 2013; 103: 1685-1692. doi: 10.2105/AJPH.2012.300941.

9. Patten CA, Albertie ML, Chamie CA, et al. Addressing community health needs through community engagement research advisory boards. Journal of Clinical and Translational Science 2019; 3: 125-125. doi: doi.org/10. 1017/cts.2019.366.

10. Stewart MK, Boateng B, Joosten $\mathbf{Y}$, et al. Community advisory boards: experiences and common practices of clinical and translational science award programs. Journal of Clinical and Translational Science 2019; 3: 218-226. doi: 10.1017/cts.2019.389.

11. Budd J, Miller BS, Manning EM, et al. Digital technologies in the publichealth response to COVID-19. Nature Medicine 2020; 26: 1183-1192. doi: 10.1038/s41591-020-1011-4

12. Noonan D, Simmons LA Navigating nonessential research trials during COVID-19: the push we needed for using digital technology to increase access for rural participants? Journal of Rural Health 2020. doi: 10.1111/ jrh. 12446.

13. Darmawan I, Bakker C, Brockman TA, Patten CA, Eder M The role of social media in enhancing clinical trial recruitment: scoping review. Journal of Medical Internet Research 2020; 22: e22810. doi: 10.2196/22810.

14. Topolovec-Vranic J, Natarajan $\mathbf{K}$ The use of social media in recruitment for medical research studies: a scoping review. Journal of Medical Internet Research 2016; 18: e286. doi: 10.2196/jmir.5698.

15. Perrin A, Anderson M Share of U.S. adults using sodial media, including Facebook, is mostly unchanged since 2018 [Internet], 2019 [cited May 15, 2020]. (https://www.pewresearch.org/fact-tank/2019/04/10/share-of-us-adults-using-social-media-including-facebook-is-mostly-unchangedsince-2018/)

16. Schneider IE, Quick K, Peck M, Pflughoeft B Effective social media engagement options for Minnesota's diversifying population. Final report 2018-08 [Internet], 2018 [cited May 15, 2020]. (http://www.dot.state.mn. us/research/reports/2018/201808.pdf)

17. Balls-Berry J, Quirindongo-Cedeno O, Aleman M, Grassie S, Valdez Soto M Community health listening session: a quality improvement project to improve the health of residents in Olmsted County, Minnesota. Presented at Mayo Clinic Quality Academy; 2014.

18. Olmsted County Health Department, Olmsted County Community Health Needs Assessment Data Sub-Group. Community health needs assessment listening sessions: Preliminary report. 2016.

19. Valdez Soto M, Balls-Berry JE, Bishop SG, et al. Use of web 2.0 social media platforms to promote community-engaged research dialogs: a preliminary program evaluation. JMIR Research Protocols 2016; 5: e183. doi: 10.2196/resprot.4808.

20. Eder M, Patten CA, Brockman TA, et al. Public feedback on a proposed statewide virtual translational research community. Journal of Clinical and Translational Science 2020; 4: 416-424. doi: 10.1017/cts.2019.417.

21. Centers for Disease Control and Prevention (CDC). CDCSocialMediaWorks: Developing a strategy for using social media [Internet], 2016 [cited Nov 18, 2020]. (https://www.cdc.gov/socialmedia/ Tools/guidelines/pdf/SocialMediaToolkit_BM.pdf?source=govdelivery)

22. Centers for Disease Control and Prevention (CDC). Facebook guidelines and best practices [Internet], 2019 [cited Nov 15, 2020]. (https://www.cdc. gov/socialmedia/tools/guidelines/facebook-guidelines.html)

23. Pagoto S, Waring ME, May CN, et al. Adapting behavioral interventions for social media delivery. Journal of Medical Internet Research 2016; 18: e24. doi: 10.2196/jmir.5086.

24. Corliss R Photos on Facebook generate $53 \%$ more likes than the average post [Internet], 2012 [cited Sept 9, 2020]. (https://blog.hubspot.com/ blog/tabid/6307/bid/33800/Photos-on-Facebook-Generate-53-More-LikesThan-the-Average-Post-NEW-DATA.aspx)

25. Strekalova YA, Krieger JL A picture really is worth a thousand words: public engagement with the national cancer institute on social media. Journal of Cancer Education 2017; 32: 155-157. doi: 10.1007/s13187-015-0901-5.

26. Facebook. 2021. Retrieved from: https://developers.facebook.com.

27. Torossian $\mathbf{R}$ How many followers do you need to be an influencer? [Internet], 2020 [cited Nov 18, 2020]. (https://www.agilitypr.com/ pr-news/public-relations/how-many-followers-do-you-need-to-be-aninfluencer/)

28. U.S. Census Bureau. Geography program: urban and rural [Internet], 2018 [cited Oct 1, 2019]. (https://www.census.gov/programs-surveys/ geography/guidance/geo-areas/urban-rural.html)

29. U.S. Census Bureau. US Census Bureau, quick facts, Minnesota [Internet], 2019 [cited Nov 18, 2020]. ( https://www.census.gov/quickfacts/fact/table/ MN/PST045219)

30. Anderson M, Perrin A, Jiang J, Kumar M. 10\% of Americans don't use the internet. Who are they? [Internet], 2019 [cited Nov 18, 2020]. (https:// www.pewresearch.org/fact-tank/2019/04/22/some-americans-dont-usethe-internet-who-are-they/)

31. Minnesota Department of Administration. Greater Minnesota: refined \& revisited [Internet], 2017 [cited Nov 11, 2020]. (https://mn. gov/admin/assets/greater-mn-refined-and-revisited-msdc-jan2017_tcm36273216.pdf)

32. Nguyen MH, Gruber J, Fuchs J, Marler W, Hunsaker A, Hargittai E Changes in digital communication during the COVID-19 global pandemic: Implications for digital inequality and future research. Social Media + Society 2020; 6: 2056305120948255. doi: 10.1177/205630 5120948255.

33. Gruzd A, Haythornthwaite C Enabling community through social media. Journal of Medical Internet Research 2013; 15: e248. doi: 10.2196/jmir.2796.

34. Auxier B 8 facts about Americans and Instagram [Internet], 2020. (https:// www.pewresearch.org/fact-tank/2020/10/21/8-facts-about-americans-andinstagram/) 